\title{
Path Choice of Psychological Counseling for "Problem College Students"*
}

\author{
Shuyang Sun \\ Baicheng Normal University \\ Baicheng, China
}

\begin{abstract}
Psychological counseling education is a communicative work mode based on human nature, which reflects on various traditional modes. It is a new value concept of ideological and political work in the new era. It is the main way to carry out psychological counseling education to get students learnt to think in another person's position, to adopt the methods of "touching one's feelings and understanding one's reason", and to grasp the appropriate time and space.
\end{abstract}

Keywords-ideological and political work; psychological counseling; education

\section{INTRODUCTION}

In recent years, the number of psychological problems faced by college students is increasing. If they are not solved in time, they will accumulate into big problems. If students' minor psychological problems are not rescued, they will cause a group problem. At present, although the psychological counseling system in colleges and universities is not perfect, some achievements have been made. Psychological counseling carried out by colleges and universities contains rich contents and is constantly adjusted according to the changing times and social development needs. At present, paying attention to humanistic care and psychological counseling has become an urgent requirement of the times and social development for ideological and political education work, which is not only the driving force of expanding the content system, but also the internal idea that expanding the content system should follow.

Ideological and political education requires the enhancement of human subjectivity, the promotion of allround development, and the enhancement of humanistic spirit, all of which promote the constant enrichment of psychological counseling content. First of all, psychological counseling in colleges and universities not only focuses on ideological counseling, but also on emotional counseling. Ideological and political education in universities needs to have a deeper understanding of ideological and psychological problems and special methods to deal with them, while ideological problems need to be solved by means of adapting to their own characteristics. For this point, the previous psychological counseling in colleges and

*Fund: This paper is the phased achievement of the social science research project "Research on Psychological Counseling Countermeasures of Problem College Students" of the Education Department of Jilin Province in the 13th Five-year Plan. universities often used a variety of appropriate methods to guide people with psychological disorders to rethink and position their world outlook, outlook on life and values, make them realize their wrong thoughts, and promote them to change to the right direction, so as to solve their ideological problems. Emotion is the main force in human spiritual life and the basis of people's normal life. With the rapid development of the current society, people are facing more and more pressure, and healthy emotions are becoming increasingly important. "Emotions are the reflection of people's attitude towards objective things and themselves". "Without human emotions', there has never been and cannot be the pursuit of truth". Healthy emotions are conducive to giving full play to people's subjective initiative and creativity. "Inner emotions or emotions are the root of all behaviors" has a great impact on people's value orientation and behavior choice. Therefore, colleges and universities attach great importance to emotional counseling when carrying out psychological counseling, and help people form healthy psychology through emotional communication. People are guided to be tolerant, tolerant of others and keep themselves positive and optimistic. Second, the psychological counseling in colleges and universities also pay attention to carry out adaptive cultivation to the student, many students live in campus due to long-term, often appear after graduation is not adapt to the situation of the society, resulting in a series of psychological problems, therefore when conducting psychological counseling in university, this factor should be noticed to help students to understand causes of these problems so as to solve psychological problems, gradually adapt to the society. The content of psychological counseling in colleges and universities is constantly enriched, which is conducive to better solving the psychological problems of college students and promoting their healthy growth of body and mind.

Ideological and political work, as the lifeline of all work, is in a double transformation of the Chinese scene, and is full of many paradoxical colors. On the one hand, the traditional model continues to play out; on the other hand, people must have the unique teaching consciousness and the political consciousness, with suits the political question solution method to deal with the existence cannot solve the question. Psychological counseling education is a communicative working mode based on human nature and reflecting on various traditional modes. It is a new value concept of ideological and political work in the new era. This 
proposition is put forward and formed, reflecting Chinese Communist's ideological and political work has always adhered to the principle of "putting people first" and the spirit of keeping pace with the times. It not only indicates that Chinese Communist party has new thoughts and new understanding on how to strengthen and improve the ideological and political work in the new period, but also points out the direction for our party to strengthen and improve the ideological and political work in the new period.

\section{ACCURATELY GRASPING THE CORE MEANING AND BASIC CHARACTERISTICS OF PSYCHOLOGICAL COUNSELING EDUCATION}

As a new mode and new value concept of ideological and political work in the new era, psychological counseling education is the premise and basis for scientific development of ideological and political work and improvement of its effectiveness.

\section{A. The Core of Psychological Counseling Education}

The so-called "dredge", as the name implies is "dredge, guide." The idea of "psychological counseling", mainly refers to workers through interpretation, instructions, compassion, support and understand each other, using verbal and nonverbal communication, mental state to influence each other, improve or change the social public, not just people with psychological problems) of cognition, belief, emotion, attitude and behavior, etc., to achieve early warning, reduce and remove the bad psychological state. Its core contents include: first, the logical starting point of psychological counseling education is to pay attention to human nature in a high and comprehensive way. Ideological and political work is a man's work, and it can be said to be a "human science", so pay attention to human nature, follow human nature is the inevitable requirement of modern ideological and political work. Different modes of ideological and political work have different assumptions of human nature, and psychological counseling education shows that the high degree and comprehensive attention to human nature is consistent with Marx's cognition of human nature, which is also the logical starting point. With the development of society, the defects of "misunderstanding" and "neglect" of human nature in traditional ideological and political work have been exposed increasingly, which greatly affects the effectiveness of ideological and political work.

Psychological counseling education abandons the onesidedness and narrowness of traditional ideological and political cognition of "human nature", emphasizes that human beings are the unity of nature, sociality and spirituality, emphasizes comprehensive grasp of human nature connotation, and pays high attention to rational publicity and free development of human nature. Second, the core values of psychological counseling education are equality and respect. Human beings as individuals are different in appearance, birth, physical strength, intelligence or acquired wealth and social status. However, as citizens of socialist countries, they are equal in legal status and personal dignity. From the perspective of philosophy, ideological and political workers, as the subject of ideological and political work, are in the position of logic first relative to the object of work. However, this is just a logical first, which does not mean that ideological and political workers can apply their political wishes and subjective wills to others. In the information age, ideological and political educators are no longer knowledge authorities, no longer the dominator of the educational process, no longer the opposite of the educated, but "the chief among equals". Ideological and political workers should understand that educators must first learn to treat others equally and respect others. Equality and respect are the core values of psychological counseling education. Thirdly, communication and dialogue are the thoughts of psychological counseling education. "As traditional ideological and political education is based on the dichotomy of subject and object in traditional philosophical epistemology, educators and educated people are often in an unequal position and lack of necessary communication and dialogue with the social and economic development", emphasizes the autonomy of the market economy, competitive, equality and openness, people must break all the attachment and attachment concept, strengthen the consciousness of independent and autonomous ability, and according to their own will and desire, independently engage in the production and business operation and market exchange, calling people full development of subjectivity and play." And in modern society, with the quickening pace of life, competition intensifies, the lack of communication and communication between human beings, the recognition and trust each other greatly reduced, the ideal faith and values, great changes have taken place in people their own inner conflicts intensified, which virtually increased the difficulty of ideological and political work, and the change of the work way of thinking is imperative. Mao Zedong had always advocated that ideological and political education should adopt the policy of "letting go" and let people speak freely. Psychological counseling education is a kind of rational reflection to the old work ideas and actively exploration and bold innovation, it advocates the ideological and political workers paid close attention to psychological changes and ideas in the mind of people, seek communication channels, develop positive dialogue, strengthen understanding, trust and sincere solidarity, to understand inspire confidence, so as to enhance the actual effect of ideological and political work.

\section{B. Characteristics of Psychological Counseling Education}

Psychological counseling education, as a mode of communication, has not only the common characteristics of ideological and political education, but also its unique characteristics. Psychological counseling is a very important means of therapy, which is implemented through communication and dialogue. There are a series of means of counseling, strong purpose and planning, psychological counseling education is still a long-term project, which cannot be completed at one time. All elements of the channeling process are organized by goals. Without specific goals, other factors cannot form an activity system. If you look at any problem, if you don't grasp the expected goal, you can't tell whether the behavior is orderly or disorderly. Psychological counseling education is progressive according 
to a certain direction, which is also dominated by a certain expected purpose. The effectiveness of psychological counseling education depends not only on the actual state of both the educator and the educational object, but also on the prediction of the future counseling effect.

\section{Constructive Characteristics}

In a sense, psychological counseling education is the reconstruction of the cognitive structure of educational objects. In the process of psychological counseling education, rebuilding the confidence of educational objects is an important condition to ensure the normal operation of the system. Once the educational object has rebuilt the selfconfidence, has the good psychology to accept the condition, is easy to mobilize them to accept the education the enthusiasm. Self-confidence can stimulate and strengthen the inner motivation of the educational object and make it cooperate with the educator actively. Self-confidence can make the educational objects consciously control their attention and willpower, closely relate to their own experience, and be absorbed in the educational activities. However, the confidence construction of educational objects comes from the proper dredging and effective guidance of educators. In order to build the self-confidence of the educational objects, people should deepen their understanding of the nature of psychological problems and cultivate and exercise their will. Educators should pay particular attention to language scientificity and interestingness, so as to make psychological education in a vivid and lively atmosphere, so as to mobilize educational objects to think and discover themselves, and make them constantly produce new insights in the process of education. This new understanding indicates that the psychological state of the educational object has entered a new high level, and it is also the concrete embodiment of the constructiveness of the whole psychological counseling education.

\section{Dynamic Characteristics}

The dynamics of psychological counseling education means that educators should not only pay attention to the current psychological status and development of educational objects, but also pay attention to its occurrence and development process. As a living organism, the basis of human body and mind balance is the constant internal renewal and adaptation to the external environment, as well as the continuous activities and exchanges of material flow, energy flow and information. Of course, people as an organizational system can also show relative stability, but this stability is relative, stable state containing absolute motion. For example, people's psychological and social tolerance is not fixed at a certain point or line, nor is it changed overnight. Under certain conditions, it always shows certain tendency and steady-state characteristics. Such tendency and steady-state will change with the continuous improvement of social environment and psychological quality. Psychological counseling education only fully grasps this kind development law and maintains a dynamic followup, to achieve the desired purpose.

\section{ThE BASIS OF PSYCHOLOGICAL COUNSELING EDUCATION}

Psychological counseling education is thought and method for the traditional ideological and political work and sublation, a meaningful reflection is the development of thought of Marxist theory and rich, is Chinese Communist's in the new era to solve contradictions among the people, "to unite all can unite the people and mobilize all positive conditions and methods, and insist on airing, brainstorming and persuading education, instilling the guiding ideology and code of conduct" of combining the ideological and political work is Chinese Communist's scientific summary of experience, reflecting the inherent regularity ideological and political work.

In the new historical period, it is determined by the ideal of building a socialist harmonious society. To be able to build a harmonious society in which all classes and all classes can live in peace and common and harmonious governance is a major task put forward by our Party in the overall context of building a moderately prosperous society in all respects and creating a new situation for the cause of socialism with Chinese characteristics. It is also the goal pursued by ideological and political work and is an important basis for psychological education.

First, psychological counseling education is conducive to people's own harmony, and social members' own harmony is the basic premise of social harmony. If the members of society can't get along harmoniously, then the whole society will not get along peacefully. With the acceleration of the pace of life in modern society, the pressure of competition intensifies, the social security is weak, and it is difficult to grasp the fate of individuals, leading to the collapse of some people's spiritual homes and soul loss. To some extent, individual psychological problems are the loss of harmony. Ideological and political workers use the psychological counseling education communication mode, by listening to, understanding, communication, dialogue, questions and reconciling knot, solving contradiction, psychological balance, to create a good mind world and the mental environment, provide their own survival and development needs of spiritual comfort, soul settle, so as to promote their harmony.

Second, psychological counseling education is conducive to harmony between people. Harmony between people is the solid foundation of social harmony, and optimizing interpersonal relationship is an effective way to build a harmonious society. During the key economic and social transformation period in China, because the public ownership as the main body, a variety of ownership economy common development of the basic economic system, the organization form, way of employment, interest and distribution methods increasingly diverse, and inevitably, different economic interests appear. In addition, the corresponding system construction is not perfect, the interpersonal relationship has become increasingly complex, economic status and contradictions are constantly widening. In particular, the sharp contrast between poverty and luxury in real life, and between hard work and illegal wealth, has 
led to people's inner sense of injustice and psychological gap. It is impossible for people to rely on law and system to solve the inharmonious factors in a short period of time.

\section{THE IMPLEMENTATION OF MAIN PATH OF PSYCHOLOGICAL COUNSELING EDUCATION}

To carry out ideological and political work in the new era, strengthen people's mental health awareness, and improve the level of mental health, so that psychological counseling education can be effective, ways must be explored to strengthen psychological counseling education, in order to solve the people's psychological problems in time. How effective the ideological and political work is, first of all, whether it can understand the characteristics of the ideological dynamics and behavioral changes of educational objects, which is a problem to be solved in the method of "disengaging". Only the correct solution of the "sparse", can accurately "guide", so that the dredging of psychological problems can be a kind of urgent and strong guide to students inner balance.

\section{A. Learning to Put Yourself in Others' Shoes}

Psychological transposition thinking is to emphasize the position of the position, the role of upside down to think about the problem, for the "sparse" to find opportunities, for the "guidance" clear direction. The idea of changing positions in education in psychological counseling means that educators should stand up and think about problems, analyze problems, and judge issues from the standpoint of the object of education, so as to increase mutual communication, communication, and understanding, and find practical points of common understanding, common ground, and resonance. Then form each other's role identity, view identity and value identity, to achieve the goal of psychological transposition. In order to achieve this goal, it is necessary to treat differences between people correctly, that is, respect for people, which is also the basis for psychological transition. In real life, as long as it is a person, whether or not life is good or bad, it will encounter various kinds of psychological pressure in daily life such as work and learning. Stress is a normal psychological phenomenon that everyone may experience. People's personality weakness and lack of ability cannot be expressed simply through psychological pressure and response. As an educator (leader) of ideological and political education, we should establish the correct concept of education, that is, the object of education is also the subject of education. From the perspective and vision of educational objects, they exchange ideas and discuss issues on an equal footing, and communicate with their hearts and emotions on an equal basis, so that the subject and the object form a good and effective interaction. In the specific work, the relationship between the upper and lower levels is changed into an equal relationship, and they are honest with each other, sincere, friendly to others, and can be persuaded to have a basis. Only in this way can they better express their true feelings and ideas.

\section{B. Enlightening Them with Affection and Motivating Them with Reason}

To "move your heart and understand your reason" is to "persuade people by emotion and reason", which is an important method to carry out ideological and political work, as well as a key link in psychological counseling education. Educators in psychological counseling education should pay special attention to listening, in-depth, real understanding of the needs of educational objects. Educators in psychological guidance education should pay special attention to listening, in-depth, and truly understand the needs of education objects. Educators should use their own sense of truth to bring themselves into the same dimension as the objects of education in order to bring them closer to each other, enhance their rational persuasion and appeal, arouse the hearts of the educatees, and inspire them in a relaxed and pleasant atmosphere, in order to achieve the ideal effect of love and love, love and love, love and affection. Under practical conditions, ideological and political work is not only an incentive for political education, but also a psychological comfort inducement. Through in-depth and meticulous ideological and political work, people can understand the ideological dynamics of educational objects and help them to face and solve the difficulties in their thinking, so as to encourage educational objects to keep moving forward, and benefit each other a lot. Therefore, ideological and political educators must consider from the perspective of practical problems of the educational objects and put an end to pure theoretical education. They should combine the role of educational counseling with the role of psychological care, give play to the role of $1+1$ is greater than 2, further enhance the cohesion and cohesion of psychological counseling education, so that education objects can fully understand themselves, improve themselves, enhance self-confidence and communicate with others, so as to eliminate psychological confusion and psychological problems. In the communication with others, the educational objects can learn from others and improve themselves constantly, so as to establish their own interpersonal relationships.

\section{The Appropriate Approach to Time and Space}

People with personality disorder may have various negative emotions under the influence of other factors, such as indecision, vulnerability and loneliness, lack of assertiveness, emotional instability and so on. Emotion is a form of reflection to objective reality and an experience generated by whether objective things meet people's needs and desires. Emotion has a direct impact on a person's mental health. If the educators take inappropriate psychological counseling to the educated at an inappropriate time, it will not only have little effect, but even is counterproductive. Therefore, educators should pay attention to the choice of time and space when carrying out education work. In the choice of time, the first problem is to see whether the conditions are mature. Talking early, talking about the subject's psychological preparation and emotional preparation is not enough, may be twice the success; Talk is late, is already the matter after autumn, and does not mean much. Especially for those with strong personality, although 
it is the same thing, due to their different personalities, the requirements for conditions are not the same. Some education objects are suspicious, and if you rashly go to talk to him heart to heart, he may have heavier alert psychology:" whether I made what big mistake again?" In such cases, educators should take a step back and look for another appropriate time; some of the objects of education are straightforward and broad-minded, so that they can consciously talk to him immediately; to be open to criticism and self-criticism, you can talk to them at any time. To stubborn objects, you should create conditions, and wait till the conditions are mature and then talk, in its psychological defense of the situation; to those who have the prejudice object to themselves, people should adopt the roundabout tactics, let the intimate colleague with the talking object to communicate first, remove the obstacle, and then look for the opportunity to talk with them again. Only in this way can psychological counseling education achieve expected results and ideological and political work be proceeded smoothly.

\section{CONCLUSION}

In a word, the essence of psychological counseling from the perspective of Ideological and political education is that the ideological and political educators represent the mainstream social thoughts to solve the ideological obstacles and ideological problems caused by the contradictions and difficulties in real life. Different from teaching and guidance, psychological counseling is to follow the law of people's ideological activities, through interpretation, explanation, communication and other ways, to clear people's ideological barriers, pay more attention to humanistic care, help to alleviate psychological pressure, promote people's health and psychological balance. Correct understanding and scientific implementation of "psychological guidance education" to enhance the effectiveness and pertinence of Ideological and political work in the new era is a realistic issue to be solved urgently in building a harmonious socialist society.

\section{REFERENCES}

[1] Ji Hong, Wang Zhifeng. Psychological health and debugging of college students. Central Compilation and Translation Press, 2006.

[2] David Myers. Social psychology. The 8th edition, People's Posts and Telecommunications Press, 2006.

[3] Xue Hao. "Problematic students" and their ideological and political work in colleges and universities. Jiangsu Higher Education, No.3, 2005.

[4] He Yuling. An analysis on utilitarianism and its influence in the current society. People's BBS, No.35, 2012.

[5] Ji Xuefeng. "The heavy edge: the connotation and cause interpretation of 'problem college students'". Journal of Social Sciences of Hunan Normal University, No.6, 2006.

[6] Liu Sujin. Philosophical reflections on youth issues. Youth Studies, No.7, 1995. 